\title{
Effect of CALL-based and Non-CALL Based Methods of Teaching on L2 Vocabulary Learning
}

\author{
Effat Bagheri \\ Faculty of Literature and Humanities, Islamic Azad University, Najafabad Branch, Esfahan, Iran \\ Email: bagheri.ssi@gmail.com \\ Ali Roohani \\ English Department, Shahrekord University, Shahrekord, Iran \\ Email: roohani.ali@gmail.com \\ Dariush Nejad Ansari \\ English Department, Faculty of Foreign Languages, University of Isfahan, Esfahan, Iran
}

\begin{abstract}
The use of Computer Assisted Language Learning (CALL) in the field of education has increased remarkably in recent years due to the swift and modern changes in language software. However, CALL is not widely employed in the field of second/foreign (L2) language learning in Iran. Interested in the application of CALL, this study examines two methods of vocabulary teaching/learning (CALL-based versus non-CALL based) in the short and long-term learning in the area of $L 2$ vocabulary. It seeks to see which method is more effective for teaching English vocabulary to young elementary Iranian EFL learners. To this end, 61 female Iranian EFL learners participated in the study through a purposive sampling. They were randomly assigned into CALL-users $(n=32)$ and non-CALL users $(n=29)$ and posttest control group design was employed. To collect data, a proficiency test was used to homogenize the participants and a multiple-choice vocabulary test was used as immediate and delayed posttests to find out the effectiveness of the methods in a shorter and longer period of time. The results of $t$-tests indicated that there was not a significant difference between the vocabulary scores of the CALL-users and non-CALL users in both short-term and long-term learning despite the fact that both methods appeared to be effective. Furthermore, both methods were found to be more effective in the short-term learning. Finally, the pedagogical implications of this study for $L 2$ teachers and learners are presented.
\end{abstract}

Index Terms - CALL, CALL-users, non-CALL users, L2 vocabulary learning, long-term learning, short-term learning

\section{INTRODUCTION}

According to Richards and Renandya (2002) vocabulary is a core component of language proficiency, and provides much of the basis for how well learners speak, listen, read, and write. Without an extensive vocabulary and strategies for acquiring new vocabulary, learners often achieve less than their potential and may be discouraged from making use of language learning opportunities around them such as listening to the radio, listening to native speakers, using the language in different contexts, reading or watching television. As Schmitt (2000) states, learning vocabulary is an essential part of mastering a second/foreign (L2) for both students and teachers. Concerning English, Zhang (2009) states that the effective learning of new English lexical items seems to be one of the major aims for learners of English. It is difficult to conduct a message or communicate in English with those who may know some grammar, but their vocabulary knowledge is poor. Research on vocabulary in recent years has done a great deal to clarify the levels of vocabulary learning learners need to achieve in order to read both simplified and non-simplified materials and to process different kinds of oral and written texts, as well as the kinds of strategies learners use in understanding, using, and remembering the words.

In addition, incorporating technology, such as computers, into the learning process as well as the wide access to internet might assist learners to improve their L2. According to Bangs and Cantos (2004), in the age of information and communication technology (ICT), computer literacy is a demand. The university needs to produce graduates equipped with ICT skills. Hence, integrating computers into the language learning process, which can offer a more powerful and authentic language learning environment, might be one of the ways to assist EFL learners to meet their demands for language skill and vocabulary learning. According to Ahmad, Corbett, Rogers and Sussex (1985), using computers offers certain advantages to language teachers as they allow teachers to process and present authentic materials with flexibility. One way of vocabulary learning, which might be of interest to language instructors and learners, is Computer-Assisted Language Learning (CALL). CALL is an approach to language teaching and learning in which the computer is used as an aid to the presentation, reinforcement and assessment of material to be learned, usually including 
a substantial interactive element (Davis, 2002). It is the search for and study of application of computer in language teaching and learning. As Seljan, Banek, and Spirance (2009) states, CALL has entered the integrative phase where computer is not only used as media for delivering instructions as in behavioristic phase or as a tool in communicative phase, but integrates multimedia packages, CD- ROMs and internet supporting skill-based activities, interactive learning and self-asses as an approach in teaching and learning. According to Levy (1997), vocabulary learning has always been a popular subject in CALL programs, especially in the early stages of CALL when technology was relatively simple and it was thought that vocabulary learning could be easily integrated into CALL program.

Since English is an international language, and the number of people who are learning it is increasing across the world, and one important component of every language is learning its vocabulary, the present research seek to apply CALL in the area of vocabulary learning, which is rarely researched in an EFL context in Iran. This study puts two methods of vocabulary learning (i.e., CALL-based and non-CALL) under spotlight and explores which of these two methods of vocabulary learning, help EFL learners to maximize their range of vocabulary in a short and longer period of time. In doing so, it draws attention to the (in)effectiveness of CALL for L2 vocabulary learning/teaching. Based upon a few studies on CALL, it is assumed that learning English vocabulary via CALL helps EFL learners to maximize their knowledge of vocabulary in short and long term-learning. However, the findings on the above issue are not quite consistent.

\section{LITERATURE REVIEW}

Computers entered the educational system in the early 1960s when they could be found in some of universities which had the departments of computer sciences. CALL is one of the fields whose progress has been influenced by the advancement in technology. During the first two decades of computer use, CALL was based on programmed instructions, which was teacher-centered. It originated from Computer Assisted Instruction (CAI), which was first viewed as an aid for teachers in 1960's (Lepper \& Gurtner, 1989). CAI allowed for dynamic presentation of materials, individualized instruction and a level of engagement in the learning process that might not be possible in a more traditional classroom setting. According to Mathes, Torgesen, and Allor (2001), CAI could provide immediate feedback regarding correct responses, reinforcement where appropriate and modeling when needed.

Up until the late 1970s, as Davies, Hewer, Rendall, and Walker (2004) state, CALL projects were confined mainly to universities, where computer programs were developed on large mainframe computers. In the late 1970, the arrival of personal computer (PC) brought computers within the range of a wider audience, resulting in a boom in the development of CALL programs. Consequently, Computer Assisted Language Instruction (CALI), which was the earlier name of CALL, changed into a new term (i.e., Computer Assisted Language learning or CALL). The philosophy of CALL put a strong emphasis on student-centered lessons that allowed the learners to learn on their own using structured and unstructured interactive lessons. These lessons carried two important features: bidirectional (interactive) learning and individualized learning. During 198s, CALL widened its scope, embracing the communicative approach and range of new technologies. CALL has now established itself as an important area of research in higher education and is used for learning various skills and components of language by the use of multimedia software.

Accordingly, there are different approaches to CALL. Traditional CALL programs, according to Matthew (1994), present a stimulus to which the learner had to provide a response. In early CALL programs, the stimulus was in the form of text presented on screen, and the only way in which the learner could respond was by entering an answer at the key board. Some programs were very imaginative in the way text was presented, making use of color to highlight grammatical features and movements to illustrate points of syntax. Discrete error analysis and feedback were a common feature of traditional CALL. Explorative CALL, which is a more recent approach to CALL, favors a learnercentered rather than a teacher- centered drill-based approach to CALL. The explorative approach is characterized by the use of concordance programs in the language classroom (Davies, et al. 2004). Multimedia CALL makes it possible combine sound, photography, still images and video recording in imaginative presentations. In this approach, learners can use interactive video discs. According to Davies et al.(2004), a feature of many multimedia CALL programs is the role-play activity, in which the learner can record his/her own voice and play it back as part of a continuous dialogue with a native speaker. Web-based CALL makes use of web activities in language learning and teaching. Web-based CALL approach can be integrated with other approaches to create hybrid approaches to CALL.

Using computer technology with the aim of helping language learners to learn vocabulary is one of the ways in which CALL has been used in language education. Licenjacka and Filologia (2007) investigated two alternative methods of learning words (i.e., traditional and CALL-based). The control group was asked to study a series of adjectives within a period of seven days without any access to technological equipment and the word processing software. They were left free to memorize the lexis in the way they chose themselves. But, the experimental group was given the access to the word processing and the opportunity to learn the new lexicon via computers in seven days. The results of the study showed that the experimental group had a better performance in terms of learning adjectives. Also, Pelletreau (2006) examined the opportunities in which intermediate English as second language learners had to acquire vocabulary while reading preselected texts using a computer program as part of their course in an English language institute. Students received an individualized series of documents containing target words. The target words consisted of a list of academic words that students did not know. Students were told explicitly to try to learn the meanings of their target vocabulary 
words by clicking on them in order to view online dictionary definitions. Students were engaged in the explicit learning of target words, though in doing so, they were given the opportunity to use the same online dictionary to look up other non-target words. Data was collected through observations of students, teacher feedback and student-student interviews. The quantitative and qualitative analysis revealed a variety of student learning outcomes and behaviors. There was no relation between non-target and target vocabulary learning outcomes. Students exhibited one of two distinct vocabularylearning behaviors: One group of students took notes while reading and focusing more on target words and the other mainly asked their teacher vocabulary questions while reading.

Getkham (2004) compared the vocabulary performance of two groups of students: One group used a multimedia computer program and the other one used traditional printed texts. Results indicated that both groups improved their vocabulary knowledge after practicing vocabulary exercises, but the students in both groups forgot some words after one month. However, the degree of forgetting of vocabulary in the group which used multimedia was less than that of the group which used printed texts. This was determined by comparing the results of an immediate posttest and a delayed posttest. The researcher concluded that a multimedia computer program could help students retain vocabulary information.

In another study, Aist (2002) used computer-assisted oral reading to help children learn vocabulary. He built a project LISTENN'S Reading Tutor, a computer program that would adapt automatic speech recognition to listen to children reading aloud, and helps them to learn to read. To learn a word from reading with the Reading Tutor, students had to encounter the word and learn the meaning of the word in context. He compared the Reading Tutor to classroom instruction and to human-assisted oral reading as part of a yearlong study with 144 second and third graders. He found that second graders did about the same on word learning in all three conditions. However, third graders who read with the Reading Tutor performed significantly better than other third graders in a classroom control and even comparably with other third graders who read one-by-one with human tutors.

Also, Iheanacho (1997) examined the effects of two multimedia CALL programs on vocabulary acquisition. Participants were 86 intermediate level English as a second language (ESL) students. They were randomly assigned to one of two treatment groups. Students in group one viewed a program with Motion Graphics and text. Students in group two viewed a program that had Still Graphics and text. Their task was to study the names of objects and tools. Both groups took the pretest, viewed the video of the tools and had an immediate posttest and a two-week delayed posttest. The results yielded no treatment effects. Further analysis revealed significant time effects, but no significant interaction between the treatment and time. Students who learned through Motion Graphics performed significantly better on the recall tests than those who learned through Still Graphics.

Gan, Low and Yaakub (1996) conducted a comparative study on the effectiveness of computers in teaching vocabulary. Forty-eight subjects were randomly divided into the control and experimental groups. A pretest posttest experimental design was used. The treatment was carried out in two stages, each of which lasted for five weeks. In each stage, the subjects were involved in five 2-hour sessions of computer assisted exercises. The control group participants were taught the vocabulary in a conventional manner, while the experimental group students were instructed by both conventional and computer mediated methods. Besides posttest exams, a questionnaire was administered at the end of the treatment to find out about the students' preferences regarding the two methods of instruction. The posttest results showed that vocabulary skills were more effectively taught by the computer assisted approach than with the conventional classroom instructional approach. The answers of the students to the questionnaire questions revealed that they preferred computer-assisted approach to be used as a complement to conventional classroom instruction in vocabulary skills. The researchers concluded that computer assisted approach could enrich the multi-context vocabulary learning experience.

In an Iranian EFL context, Shahrokni (2009) studied the effect of online textual, pictorial, and textual pictorial glosses on the incidental vocabulary learning of 90 adult elementary Iranian EFL learners. The participants were selected from a pool of 140 volunteers based on their performance on an English placement test as well as the knowledge test of the target words in the study. They were randomly assigned to three groups of 30 and subsequently exposed to the research treatment. During three sessions of instruction, five computerized reading texts including 25 target words were studied. The participants read the text for comprehension and, at the same time, were able to consult the glosses attached to the target words. Having read each text under each research condition, the participants were tested on their incidental vocabulary learning through two research instruments, word and picture recognition tests. The results of a one-way ANOVA analysis of the data indicated that a combination of text and still images resulted in significantly better incidental learning, confirming the Dual-Coding Theory. In another study, Ghabanchi and Anbarestani (2008) investigated whether CALL programs have any effect on the long-term retention in vocabulary learning, and whether CALL programs have a better effect on contextualized vocabulary learning than the ordinary method of learning vocabulary in isolation through bilingual lists. Fifty-six EFL students participated in their study. Among the participants, nearly 28 students who had access to personal computers at home were voluntarily selected. This group made the experimental group, and the others made the control group. The experimental group used technological apparatus and computerized facilities at home to find meaning and definition of nearly taught words and to use them. However, the control group followed the ordinary method for finding the meaning of new words. This group used desktop dictionaries and students could make a bilingual list of new words to memorize them. The teacher 
taught every session 30 new words. He gave both groups their definition, pronunciation, and some synonyms and antonyms. The result indicated that learners had an intensive mental processing in using CALL, which resulted in longterm recall of words. CALL also produced better results in contextualized vocabulary learning and pronunciation. However, the scores on the immediate test were considerably higher for the control group, but the scores on the delayed tests were significantly lower for the control one.

In summary, CALL, particularly multimedia CALL, is the result of advancement in computer technology, which has made it possible to simultaneously present the different modalities to the language learners. Despite the fact that most studies on vocabulary learning support the use of CALL and point out to its positive effects, there are some studies in which non-CALL methods prove to be significant as a rival to CALL-based methods. That is the reason we should be cautious about the wild claims made on the extent of its application in L2 learning. Besides, the review of studies in the field of L2 vocabulary suggest that language researchers have carried out fewer CALL-based studies, compared with non-CALL based studies. To move further, there are fewer studies on CALL and vocabulary learning in EFL contexts such as Iran. In light of these views, it becomes clear that more research is required to shed more light on the effect of CALL on L2 vocabulary learning.

\section{PuRPose of The Study AND ReSEARCH Questions}

Utilizing computers has demonstrated significant effects on the achievement levels of language learners in recent years. This study shines light on the application of CALL in the area of L2 vocabulary. The main purpose of the study is to determine which method of vocabulary learning, (i.e., a CALL-based versus a non-CALL based method) yields in better results in teaching /learning L2 vocabulary (i.e., English vocabulary) in a short and longer period of time. In other words, the effectiveness of the above methods is investigated. Language software called Phonics constitutes the backbone of the CALL-based method, which is less familiar to young EFL learners in Iran. Therefore, the following research questions are formulated:

1. Is CALL-based instruction more effective than non-CALL-based instruction in the short-term vocabulary learning?

2. Is CALL-based instruction more effective than non-CALL based instruction in the long-term vocabulary learning?

3. Is the effect of the CALL-based and non-CALL based instruction in L2 learning retained over time?

Accordingly, the following null hypotheses were derived from the research questions of the study:

$\mathrm{H}_{01}$ : CALL-based instruction is not more effective than non-CALL based instruction in the short-term vocabulary learning.

$\mathrm{H}_{02}$ : CALL-based instruction is not more effective than non-CALL based instruction in the long-term vocabulary learning.

$\mathrm{H}_{03}$ : The effect of the CALL-based and non-CALL based instruction in L2 learning is not retained over time

\section{METHOD}

\section{A. Participants}

The main participants of the study included 61 Iranian EFL learners from a private language institute in Isfahan, Iran. They were all females and their age ranged from eleven to thirteen. They had taken two elementary language courses in the institute, which mainly focused on conversational skills. The participants who were selected through a proficiency placement test consisted of 32 CALL-users and 29 non-CALL users. They attended the language class twice a week.

\section{B. Instruments}

This study used two instruments for data collection: a proficiency placement test and a vocabulary test. In order to make sure that all participants in the study enjoyed the same level of language ability, a proficiency placement test, which was a modified version of the test developed by Lesley, Hansen \& Zukowski/Faust (2005), was used. It should be noted that the institute where the data was collected use this test, together with an interview, to place new comers into different language levels. The test included 20 multiple-choice listening, 20 multiple-choice reading and 30 multiple-choice language use items. The participants whose score were low were selected for the main trial of the study. Following the scoring guidelines by Lesley, et al. (2005), the scores below 12 (i.e., rating 3) were considered as the elementary level. The vocabulary test, which was used posttests, included 40 multiple-choice items and had a good coverage of the instruction in the course. The score of the test ranged 0-40, with each item receiving one mark for the correct answer. The validity of the vocabulary test was investigated by the expert judgments. Two experts checked the suitability of the words in test. The reliability of the whole vocabulary test, as measured by Cronbach alpha coefficient on the pretest scores with a sample of 61 participants, was .82, which is commensurate with the requirements for the reliable scoring by Larson-Hall (2010, p. 171) and Hatch and Lazaraton (1991, p. 441). The reason for this reliability of the test can be related to its good internal consistency, and homogeneity of items.

\section{Procedure}

In order to collect data for this study several steps were taken. First, the proficiency placement test was administered to 90 EFL learners in Sokhansara Language Institute in Esfahan in order to select a more homogenous group. Based on 
the proficiency scores, 81 elementary level EFL learners, whose scores were low, were selected from the sample. It should be noted that all the participants had also been interviewed by the head of the language institute before and were placed into elementary level language courses. Second, the developed vocabulary test, which had a good coverage of the instruction in two groups, was given to 20 EFL participants selected from the sample to check that the target words were unfamiliar to them. All 20 participants indicated that they did not know the meaning of the words. Thus, the desirability of the items was confirmed. Third, except two participants, who could attend only the CALL group, all other participants were randomly assigned into two groups: CALL and non-CALL. Instruction was given to the CALL group in a language laboratory equipped with 32 computers. This group used an instructional software program called phonics; the phonics software helps learners to learn pronunciation and vocabulary. Through this software, learners can also play vocabulary games. For instance, learners can do super star activity. In this activity, learners are asked questions and their correct answers are recorded in the right answer box. Every time a learner does it, he/she receives a star. If the activity is done without any wrong answers, the learner receives a gold star. If there is a wrong answer, he/she receives a silver star. It is possible for the participants to see the pictures of words, spellings of words and examples in context. Also, it is possible to practice the pronunciation of words via computers. The participants in the CALL group could learn up to thirteen words every session. They also had a regular review of the words taught in the previous session.

The non-CALL group practiced the same vocabulary taught in the CALL group, but they did it in the classroom. The teacher used paper pictures, cassette player, flash cards and other realia to teach vocabulary. Similarly, the participants in the non-CALL group could learn up to thirteen words every session. They also had a review of the words taught in the previous session. Every session, the teacher introduced new words through pictures, wrote the spellings of the words, and practiced them with the participants via a cassette player. The participants had the opportunity to use flashcards in pair group works to reinforce their learning.

Fourth, in order to check their immediate learning, the vocabulary test was administered in both groups after twenty sessions of instructions. Finally, to see the effectiveness of instructions in both groups, 20 days later the same vocabulary test was given to both groups as delayed posttests.

\section{RESULTS}

In order to compare the performance of CALL-users and non-CALL users in the short term, the means and standard deviations of immediate posttests in the CALL and non-CALL groups were obtained. The descriptive statistics of both groups are reported in Table 1. As the table displays, the mean scores of the CALL and non-CALL groups were 28.80 and 27. 50, respectively, which were rather high since the possible range of vocabulary scores, as stated before, were from 0 to 40 . Also, the vocabulary mean scores of both groups were close, indicating that the performances of both groups were not much different. In the same line, the standard deviations and standard errors of means were pretty high, but not much different, indicating that the variance in both groups was similar and vocabulary scores in both groups were widely spread.

TABLE 1.

DESCRIPTIVE STATISTICS OF CALL AND NON-CALL GROUPS

\begin{tabular}{|l|l|l|l|l|}
\hline Group & N & Mean & Std. Deviation & Std. Error of Mean \\
\hline CALL & 32 & 28.80 & 6.49 & 1.14 \\
\hline Non-CALL & 29 & 27.50 & 5.91 & 1.09 \\
\hline
\end{tabular}

In order to address the first null hypothesis of the study, stating that CALL-based instruction is not more effective than non-CALL based instruction in the short-term vocabulary learning, an independent $t$ test was conducted on the immediate posttest vocabulary mean scores of the CALL and non-CALL groups. As shown in Table 2, the difference between the mean scores was not statistically significant, $t(59)=.790, p=.433$. The observed $t(.790)$ was small and level of significance was larger than .05.

TABLE 2.

T TEST ON THE IMMEDIATE POSTTEST VOCABULARY MEAN SCORES OF CALL AND NON-CALL GROUPS

\begin{tabular}{|l|l|l|l|l|l|}
\hline Group & Mean Difference & Std. Error Difference & $\boldsymbol{t}$ & df & Sig. (2-tailed) \\
\hline CALL and Non-CALL & 1.26 & 1.59 & .790 & 59 & .433 \\
\hline
\end{tabular}

In order to compare the performance of CALL-users and non-CALL users in the long term, the means and standard deviations of delayed posttests in the CALL and non-CALL groups were obtained. The descriptive statistics of both groups are reported in Table 3. As the table displays, the mean scores of the CALL and non-CALL groups were 24.96 and 24.20, respectively, which were rather high since the vocabulary scores, as stated before, could range from 0 to 40. However, the mean scores of both groups were smaller than the immediate posttest mean scores. Also, the vocabulary mean scores of both groups were not much different, indicating that the performances of both groups were not much different. In the same line, the standard deviations and standard errors of means in the two groups were pretty high, but 
not much different from each other, indicating that the variance in both groups was similar and vocabulary scores in both groups were widely spread.

TABLE 3.

DESCRIPTIVE STATISTICS OF CALL AND NON-CALL GROUPS

\begin{tabular}{|l|l|l|l|l|}
\hline Group & N & Mean & Std. Deviation & Std. Error of Mean \\
\hline CALL & 32 & 24.96 & 5.54 & .98 \\
\hline Non-CALL & 29 & 24.20 & 6.42 & 1.19 \\
\hline
\end{tabular}

In order to address the second null hypothesis of the study, stating that CALL-based instruction is not more effective than non-CALL based instruction in the long-term vocabulary learning, an independent $t$ test was conducted on the delayed posttest vocabulary mean scores of the CALL and non-CALL groups. As demonstrated in Table 4, the observed $t$ value (.497) was small and level of significance was larger than .05. Thus, the difference between the mean scores was not statistically significant, $t(59)=.497, p=.621$.

TABLE 4.

T TEST ON THE DELAYED POSTTEST VOCABULARY MEAN SCORES OF CALL AND NON-CALL GROUPS

\begin{tabular}{|l|l|l|l|l|l|}
\hline Group & Mean Difference & Std. Error of Difference & $\boldsymbol{t}$ & df & Sig. (2-tailed) \\
\hline CALL and Non-CALL & 0.761 & 1.53 & .497 & 59 & .621 \\
\hline
\end{tabular}

In order to address the third null hypothesis of the study, stating that the effect of the CALL-based and non-CALL based instruction in L2 learning is not retained over time, two paired $t$ tests were. The first one was run on the immediate and delayed posttest vocabulary mean scores of the CALL group. The second one was run on the immediate and delayed posttest vocabulary mean scores of the non-CALL group. As displayed in Table 5, the observed $t$ value in the first test (4.27) was large and level of significance was smaller than .05. Thus, the difference between the mean scores of immediate and delayed posttests in the CALL group (i.e., 3.84) was statistically significant, $t(31)=4.27, * p$ $<$.05. Similarly, the mean difference between immediate and delayed posttests in the non-CALL group (i.e., 3.34) was found to be significant, $t(28)=5.63, * p<.05$.

TABLE 5.

T TEST ON THE IMMEDIATE AND DELAYED POSTTEST VOCABULARY MEAN SCORES OF CALL AND NON-CALL GROUPS

\begin{tabular}{|c|c|c|c|c|c|c|}
\hline & \multicolumn{3}{|c|}{ Paired Differences } & \multirow[t]{2}{*}{$t$} & \multirow[t]{2}{*}{$\mathrm{df}$} & \multirow[t]{2}{*}{ Sig. (2-tailed) } \\
\hline & Mean & Std. dev. & Std. Error Mean & & & \\
\hline $\begin{array}{l}\text { Immediate Posttest- Delayed Posttest } \\
\text { (CALL Group) }\end{array}$ & 3.84 & 5.09 & 0.90 & 4.27 & 31 & 0.00 \\
\hline $\begin{array}{l}\text { Immediate Posttest- Delayed Posttest } \\
\text { (Non-CALL Group) }\end{array}$ & 3.34 & 3.20 & 0.59 & 5.63 & 28 & 0.00 \\
\hline
\end{tabular}

\section{DISCUSSION}

Vocabulary teaching and learning were given little priority in second language programs in the past (Richards \& Renandya, 2002). The present research, however, has provided detailed and practical information about utilizing technology, in particular CALL, in the area of L2 vocabulary teaching/learning. Before the instructions (i.e., treatments) in the CALL and non-CALL groups were carried out, the participants of the study did not know the meanings of the words or had very little knowledge of the target words in the vocabulary test, but after the instructions were given to both groups, their knowledge of the target vocabulary improved greatly. This improvement in L2 vocabulary ability was demonstrated through their mean scores of both groups in the immediate posttests (28.80 and 27. 50), which were somehow closer to the maximum score rather than the minimum zero. The above result highlights the major role of the explicit teaching of vocabulary for L2 learners. Vocabulary learning is sometimes left to look after itself and receives only incidental attention in many textbooks and language programs. L2 curricula are often quite specific about aspects of teaching grammar and reading, but little specification is given to the role of vocabulary. The results of this study imply that the status of teaching vocabulary should change and more attention should be given to it. Besides, the above results suggests that both CALL-based and non-CALL based methods can be utilized in developing L2 lexical competence. The decision to select one should be left to other factors such as the competence of language teachers and analysis of situation or context in which a method is used.

Nonetheless, the first research question was formulated to see whether the CALL-based instruction would be more effective than the non-CALL based instruction in the short term vocabulary learning. The results of this study, as reported in Table 2, demonstrated that the performances of the CALL users and non-CALL users on the L2 vocabulary test were not significantly different in the immediate posttests. Thus, the first null hypothesis of the study is not rejected. This finding indicates that both CALL-based and non-CALL based methods significantly improved their L2 lexical knowledge in the short run. The above result suggests that computers can be used along with other traditional techniques to foster young L2 learners' lexical competence. The idea of sitting down on a chair and keeping the attention focused to a person or to a book is sometimes boring when it comes to children, so applying CALL in L2 
vocabulary learning plays an important role to solve this problem. However, there should not be exaggeration about the application of CALL in L2 learning. CALL can be used as an alternative classroom instructional tool. However, we should not expect great changes through implementing CALL, as compared with the traditional method of teaching vocabulary. By implication, when possible, L2 teachers can make use of computers in fostering young learners' lexical competence and adding variety to classroom activities, but when such facilities are not available, as it is often the case in Iran, they can still rely on the conventional method of using picture, cassette players, flashcards and other realia to teach vocabulary to young language learners.

Concerning the use of computers in L2 vocabulary learning, the results obtained in this study are not in agreement with the results obtained by Ghabanchi and Anbarestani (2008) and Licencjacka and Filologia (2007). In Ghabanchi and Anbarestani's study, the CALL-users used computerized facilities at home to practice and find the definitions of newly taught words, but the non-CALL users followed traditional approaches such as using desktop dictionaries to find the meanings of new words and memorizing a bilingual list of new words. The results of their study showed that the nonCALL users performed better on the immediate vocabulary test. Also, in Licencjacka and Filologia's study, the control group was asked to study a series of adjectives within a period of seven days without any access to computers, but the experimental group was given access to the words processing application and the opportunity to learn the new lexicon via computers in seven days. The results of the study showed that the superiority of the experimental group in learning adjectives. It seems that the type of CALL, proficiency and the age of learners might play a role in obtaining different results. Unlike their study, the current study used Phonics with the young elementary EFL learners. Meanwhile, a CALL-based method was used in the present study to teach the concrete words. Thus, the type of words the study is concerned with might be another reason for inconsistency of results.

On the other hand, the results obtain in the present study support the results obtained by Getkham (2004). This researcher compared the vocabulary performance of two groups of students: One group used a multimedia computer program and the other one used traditional printed texts. Results indicated that both groups improved their vocabulary knowledge after the instructions. Similarly, the young second graders in Aist's (2002) study had the same performance when used computer-assisted oral reading and human-assisted oral reading to learn vocabulary. That is, the participants' performance was not significantly different when they used the computer program and traditional method to help to learn word meanings in reading.

The second question of the research was formulated to see whether CALL-based instruction would be more effective than non-CALL based instruction in the long-term vocabulary learning. The results of this study, as reported in Table 3, demonstrated that the performances of the CALL users and non-CALL users on the L2 vocabulary test were not significantly different in the delayed posttests. Thus, the second null hypothesis of the study is not rejected. This finding indicates that both CALL-based and non-CALL based methods significantly improved their L2 lexical knowledge in the long run, given that the participants had little knowledge of the target words before the treatments of the study (i.e., instructions) were carried out. Meanwhile, the mean scores of both groups, as displayed in Table 3, decreased from the immediate posttests to the delayed posttests. This suggests that some forgetting, as expected, took place. However, the decrease in the mean scores was observed in both CALL and non-CALL groups. Hence, no significant difference in the mean scores of both groups in the delayed posttests was observed. Getkham (2004), who compared the vocabulary performance of those using a multimedia computer program and those using traditional printed texts, reported that both groups forgot some words after some time in the delayed posttests. However, contrary to the above results, his findings indicated the degree of forgetting vocabulary in the group which used the multimedia computer program was less than that of the group which used printed texts.

The third question of the research was posed to see whether the effect of CALL-based and non-CALL based instructions would be retained after a period of time. The results of this study, as reported in Table 5, demonstrated that the mean differences between the immediate and delayed posttests was large enough in both CALL and non-CALL groups. The mean scores decreased significantly from the immediate to delayed posttests. That is, the performance of both groups was lower in the delayed posttests, compared with the immediate posttests. This indicates that the effect of CALL and non-CALL based methods was not retained over time. The results obtained in the present study do not support the findings of Ghabanchi and Anbarestani's (2008) study. They investigated whether CALL programs would have any effect on the long-term retention in vocabulary learning. They found out that in the immediate vocabulary posttests, the control group (i.e., non-CALL users) had a higher mean and lower standard deviation in comparison with the experimental group (i.e., CALL-users), but in the delayed posttest, there was a significant decrease in the mean of control group. In other words, the participants who had used CALL programs had a better performance in the delayed posttests. That is, they had an intensive mental processing, which resulted in long-term recall of words. The contradictory results might be due to the type of computer programs used in various studies. The language learner variable can be another factor affecting the inconsistent results about long-term vocabulary learning. As stated before, the participants in the current study, unlike the above studies, were young and had low level of proficiency. Besides, the time interval between immediate posttests and delayed posttests vary from one study to another study. The time interval was 20 days in this study while it was 30 days in Getkham's (2004) study.

The above issue suggests the need for more research before any strong claim is made about the effect of CALL-based and non-CALL based methods in the long-term language learning. Besides, the results of this study imply that 
vocabulary learning is a long and continuous process which needs reinforcement and practice. If EFL learners do not pay attention to this aspect of language throughout their language courses, their vocabulary performance will get worse over time. L2 teachers, learners and materials developers should use or advocate a sound method to develop lexical competence. According to the results of this study, this method for young EFL learners in Iran can be either a CALLbased one, which is in line with the fast pace of technology and generates motivation among EFL learners to improve their lexical knowledge, or a non-CALL based one, which is legitimate to use in contexts where CALL is not applicable. Both methods, however, have short-term effects on lexical competence. What seems to more guarantee success in vocabulary learning is how long or how much the above methods can sustain L2 learners in vocabulary learning. Shortterm intensive vocabulary teaching courses, which are advertised by some language institutes, are not recommended. Rather, what the results of this study make us recommend is long-term programs for vocabulary learning which are juxtaposed with other language skill courses so that the transition from dependent to independent learning gradually takes place in the long process of L2 vocabulary learning.

\section{CONCLUSION}

Learning vocabulary in a foreign language is not an easy task, especially for beginning. It seems that using a sound method for teaching/learning vocabulary is indispensible. The use of multimedia technology and, in particular, CALL has recently inspired some research in the various area of vocabulary teaching/learning. In light of these views, this research put CALL under spotlight to see whether it would have potential to improve the lexical competence of EFL learners who were at the elementary level of proficiency. More specifically, it explored the effectiveness of two methods (i.e., CALL-based and non-CALL based) to teach English vocabulary to low level Iranian EFL learners. The results demonstrated that both CALL and non-CALL users benefited from the above methods in the short and long-term learning of English vocabulary; both methods had the potential to actively engage the EFL Learners in learning English vocabulary. In addition, the performances of the two groups on vocabulary were not significantly different both in the short and longer period of time. However, both groups exhibited a lower performance on the vocabulary test in the delayed posttest in comparison with the immediate posttest, indicating that the effect of instructions was not retained over time. By implication, L2 teachers should not let technological revolution pass by without using it to serve their vocabulary teaching goals whenever possible. Both CALL and non-CALL based methods can be effectively implemented in EFL classrooms if the need arises. More important, CALL or non-CALL approach should develop students into motivated, independent, reflective, strategic, confident, and competent lifetime learners of vocabulary.

\section{REFERENCES}

[1] Ahmad, K., Corbett, G., Rogers, M. \& Sussex. P. (1985). Computers, language learning and language teaching. Cambridge: Cambridge University Press.

[2] Aist, G. (2002). Helping children learn vocabulary during computer-assisted oral reading. http://www.ifets.info/journals/5_2/aist.html (accessed 15/9/2010).

[3] Bangs P. \& Cantos, P. (2004). What can computer assisted language learning contribute to foreign language pedagogy? International Journal of English Studies (IJES) 4.1, 221-239.

[4] Davis, J. N. \& Lyman-Hager, M. N. (2002). Computer and L2 reading: Student performance, student attitudes. Foreign Language Annals 30.1, 48-69.

[5] Davies, G., Hewer, S., Rendall, H. \& Walker, R. (2004). ICT4LT Module 1.4: Introduction to computer assisted language learning (CALL).http://www.ict4lt.org/en/en_mod1-4.htm (accessed 19/10/2010).

[6] Gan, S. L., Low, F. \& Yaakub, N. F. (1996). Modeling teaching with a computer based concordancer in a TESL pre-service teacher education program. Journal of Computing in Teacher Education 12.4, $28-32$.

[7] Getkham, K. (2004). The effect of using the multimedia computer program on vocabulary acquisition and retention. http://palc.ia.uni.lodz.pl/ abstract. php?paper- num=73 (accessed 14/8/2010).

[8] Ghabanchi, Z. \& Anbarestani, M. (2008). The effect of CALL program on expanding lexical knowledge of EFL Iranian international learning. Journal of Reading Matrix, 8.2, 82-95.

[9] Hatch, E. \& Lazaraton, A. (1991). The research manual: Design and statistics for applied linguistics. Boston: Heinle and Heinle.

[10] Theanacho, C. C. (1997). Effect of two multimedia computer assisted language learning program on vocabulary acquisition of intermediate level ESL students. M.A. thesis, University of Virginia.

[11] Larson-Hall, J. (2010). A guide to doing statistics in second language research using SPSS. New York: Routledge.

[12] Lepper, M. R. \& Gurtner, J. (1989). Children and computers: Approaching the $21^{\text {st }}$ century. American Psychologist 89, 170178.

[13] Lesley, T., Hansen, C. \& Zukowski/Faust, J. (2005). Interchange \& passages: Placement and evaluation packages. Cambridge: Cambridge University Press.

[14] Levy, M. (1997). Computer assisted language learning, context and conceptualization. Oxford, UK: Clarendon Press.

[15] Licenjacka, P. \& Filologia, N. K. (2007). Computer-assisted language learning. Effectiveness of vocabulary learning with the help of the author application of application of the catching practice. M.A. thesis, University of Koleguim.

[16] Matthews, C (1994). Intelligent computer-assisted Language learning as cognitive science. The choice of syntactic frameworks for Language tutoring. Journal of Artificial Intelligence in Education 5.4, 533-556.

[17] Pelletreau, T. R. (2006). Computer-assisted target and non-target vocabulary acquisition in the ESL classroom. Ph.D. dissertation, University of Miami. 
[18] Richards, J. C. \& Renandya, W. A. (2002). Current research and practice in teaching vocabulary. In J. Richards \& W. A. Renandya (eds.), Methodology in language teaching. Edinburgh, UK: Cambridge University Press, 257-267.

[19] Schmitt, N. (2000). Vocabulary in language teaching. Cambridge: Cambridge University Press.

[20] Seljan, S., Banek, M. \& Spirance, L. (2009). CALL (computer-assisted language learning) and distance learning. Journal of Language Teaching \& Research 45, 711-740.

[21] Shahrokni, S. A. (2009). Second language incidental vocabulary learning: The effect of online textual, pictorial, and textual pictorial glosses. TESL-EJ 13.3, 1-17.

[22] Mathes, P. G., Torgesen, J. K. \& Allor, J. H. (2001). The effects of peer-assisted literacy strategies for first-grade readers with and without additional computer-assisted instruction in phonological awareness. American Educational Research Journal 38, 371-410.

[23] Zhang, B. (2009). FL vocabulary learning of undergraduate English majors in Western China: Perspective, strategy use and vocabulary size. English Language Teaching 2.3, 178-185.

Effat Bagheri is an MA graduate student in TEFL. She was born in Esfahan, Iran. She received her BA in English translation in 2003 from Khorasgan University, Esfahan, Iran.

She is currently teaching English in language institutes in Esfahan. She has participated in the conferences on issues in English language teaching in Iran.

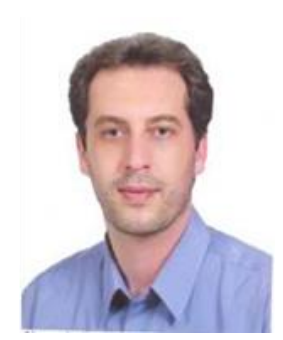

Ali Roohani is a PhD holder in teaching English as a foreign language (TEFL). He was born in Esfahan, Iran. In 1998, he received his BA in English literature from Shiraz University in Iran. He received his MA and PhD in TEFL from Shiraz and Allameh Tabataba'ii universities in Shiraz and Tehran in 2001 and 2008, respectively.

$\mathrm{He}$ is currently a member of academic staff at Shahrekord University in Iran. He has 9 years of teaching experience. His area of interest includes affective variables in L2 learning, EQ, multiple intelligence and language learning strategies. He has written and translated 3 books. He has published 10 papers and presented several papers in the national and international conferences.

Dariush Nejad Ansari is an assistant professor in TEFL at the University of Isfahan. He has been teaching TEFL courses at the University of Isfahan for 18 years. His main research interests are Language Teaching, Translation studies, and psycholinguistics. 